\title{
The Effect of an Educational Program on Nurses' Knowledge about Hepatitis B Virus (HBV) in Ninavah Covernorate Hospitals
}

\author{
Mohammed Mohammed Mustafa Wahab *
}

Taha Hassan Taha **

\begin{abstract}
Background and aims: Hepatitis B virus (HBV) considered an infectious disease that affects the liver and is transmitted by blood and body fluids. It still poses a great threat for patients. Nurses are more likely to infected the disease due to dealing with these disease. The purpose of this study is to assess the effect of an educational program on nurses knowledge about HBV and determine relationship between nurses knowledge and demographic characteristics ( gender, age, educational level, years of employment, place of work). Materials and method: A Quasi - experimental study from $28^{\text {th }}$ October 2013 to $31^{\text {st }}$ December 2014. The study sample was randomly selected consisting of (60) nurses from both hospitals, and the sample was divided into two equal groups, the study group (30) nurses in Tal Afar General Hospital and the control group (30) nurses in Ibn Sina Teaching Hospital. To assess and analyze the results of the study, a statistical package for the social sciences(SPSS) program was used through the application of descriptive statistics and inferential statistics.
\end{abstract}

Results: The results of the study showed that the effect of educational program regarding nurses' knowledge toward HBV is positive, The results also showed the differences of statistically highly significant differences in the knowledge of nurses after implementation of the educational program about HBV compared to their knowledge in the period preceding the implementation of the program in study group. The study showed that there is no significant correlation between knowledge about HBV among nurses and some of the demographic characteristics.

Conclusion: the presence of a lack in the knowledge of nurses about HBV before application educational program and after applying it, there were improvement.

Recommendations: The study recommended to activating continuing nursing education unit or medical education as well as setting points and grades for these actions and calculating the promotion and annual increment as an equivalent point.

keywords: Educational program, Hepatitis B, Knowledge and Nurses.

\section{INTRODUCTION}

Hepatitis B is a potentially lifethreatening liver infection caused by the hepatitis B virus (HBV). It is a major global health problem. It can cause chronic liver disease and chronic infection and puts people at high risk of death from cirrhosis of the liver and liver cancer) WHO, 2013). According to the World Health Organization (WHO), hepatitis B is the world's most common liver infection, which is caused by a DNA-virus, The virus is highly contagious, 50-100 times more infectious than HIV (WHO , 2012). HBV is a major cause of morbidity and mortality worldwide , and its consider one of the five important infections that causes premature death in the world(Aspinall et al., 2011; Beltrain et al., 2003). HBV causes 60$80 \%$ of liver cancer cases worldwide ( Perz et al., 2006) . Also HBV can cause both acute and chronic infection and HBV carriers are at risk for the development of cirrhosis and hepatocellular carcinoma (HCC), and patients with chronic infection require life-long monitoring (Coffin and Lee, 2006). An estimated more than 240 million people have chronic (long-term) liver infections worldwide, about 600000 people die every year due to the acute or chronic consequences of HBV(WHO, 2013). About two third of people suffering from hepatitis $\mathrm{B}$ are residing in the developing countries (Brown and Gaglio, 2003). HBV is transmitted through blood and blood products, body fluids, sharps, sexual intercourse and through vertical transmission (Nazzal and Sobuh, 2014) . People infected with HBV might not be feel sick, or might suffer loss of appetite, tiredness, muscle or stomach pains, diarrhea or vomiting and jaundice (Abraham , 2012). The risk of contracting $\mathrm{HBV}$ by health care workers(HCWs) is four-times greater than that of general adult population (Dannetun et al., 2006). .Transmission of infection from patients to health care workers like nurses was common before widespread $\mathrm{HBV}$ vaccination of health care workers (Shepard et. al., 2006). Nurses are at high risk of exposure to human blood and body fluids in their occupational environment. Injuries from sharp instruments and splashes of blood and body fluids place nurses at high risk for numerous blood-borne infections including

\footnotetext{
* MSc Candidate/ Nineveh Health Dicroterate .

** Assistant Professor / College of Medicine/ University of Nineveh.
} 
hepatitis B (Sreedharan et. al., 2010). Needle sticks and sharps injuries represent a significant hazard in professional nursing. Researches also have shown that, between all HCWs, nurses are the ones who sustain a high needle sticks injuries burden (Smith et. al., 2006). HBV can be prevented by strict adherence to standard microbiological practices and techniques, and routine use of appropriate barrier precautions to prevent skin and mucous membrane exposure when handling blood and other body fluids of all patients in health-care settings and pre-exposure vaccines. Even after many publications about programs and strategies to prevent transmission, $\mathrm{HBV}$, and $\mathrm{HCV}$ infections still remains a major public health issue for mankind (Askarian et. al., 2011). In addition hepatitis B can be prevented by HBV vaccine is $95 \%$ effective in preventing infection and its chronic consequences, and was the first vaccine against a major human cancer(WHO, 2013). Following exposure to blood or body fluids, post-exposure prophylaxis can be administered as a combination of passive immunization with hepatitis B immunoglobulin (HBIG) and vaccination with the hepatitis B vaccine(SAVIC, 2008).

\section{MATERIALS AND METHOD}

A quasi experimental research design with pre and post test to the (study, control) groups approach was used to evaluate effect of the educational program regarding HBV was carried out from $\left(28^{\text {th }}\right.$ October 2013 to $31^{\text {st }}$ December 2014).The study was conducted in Tall Afar General Hospital and Ibn Sina Teaching Hospital in Nineveh Governorate. A Probability random sample was chosen for the present study. The sample consists of (60) nurses working in both hospitals. They were divided into two groups, each group of (30) nurse who were exposed to the an educational program (study group) in Tal Afar General Hospital and another group of (30) nurse who were not exposed to the educational program and considered as (control group) in Ibn Sina Teaching Hospital. In order to prepare the assessment tools; a preliminary study was conducted in Tal Afar general hospital on (10) nurses during the period from $4^{\text {th }}$ November up to the $7^{\text {th }}$ of November 2013 . The questionnaire is constructed to be introduced to the nurses to evaluate the tools of program upon the nurses demographic information and knowledge which composed of 2 parts:. (Part I :Selfadministered questionnaire sheet related to demographic characteristics of the nurses. consisted of (5) item which included: Data related to the nurses such as age, gender, educational level and years of employment, place of work. Part II Self-administered questionnaire sheet related to nurses' knowledge toward HBV. It was constructed to assess nurses' knowledge toward HBV. The tools is mainly based on the information related to the results of the preliminary study and information obtained from literature review. which consists of (50) items for nurses knowledge about hepatitis B (concept of HBV, types of HBV, mode of transmission, signs and symptoms, risk person, complications ,treatment, prevention from the disease, universal precaution and Post exposure prophylaxis). each item has two options (Yes and No). The validity of the program and questionnaire tool was established through a panel of (15) experts of different specialties related to the field of the present study. They were asked respectively to review the questionnaire for clarity and adequacy in order to achieve the present study objective. To evaluate statistically the reliability of instruments, Pearson's coefficient of correlation was used to estimate the scale (test - re test) by using SPSS version 19.The study was carried out in Tall Afar general hospital which is the place of the study group .The Instructional program was implemented in lecture room in Tall Afar general hospital. The final step of the study is to assessment the change that occurs in nurses knowledge in response to the effect of the program. This is done through application of post-test on the study group after three weeks from the implementation of the program.

\section{RESULTS}

Table (1): Distribution of the nurse's demographic characteristics in both groups (study and control).

\begin{tabular}{||l|l|c|c|c|c||}
\hline \multirow{2}{*}{ Variables } & \multicolumn{2}{c|}{ Study group } & \multicolumn{2}{c|}{ Control group } \\
\cline { 3 - 6 } & No. & $\mathbf{\%}$ & No. & $\mathbf{\%}$ \\
\hline \multirow{3}{*}{$1-$ Gender } & Male & 18 & 60 & 23 & 77 \\
\cline { 2 - 6 } & Female & 12 & 40 & 7 & 23 \\
\cline { 2 - 6 } & Total & $\mathbf{3 0}$ & $\mathbf{1 0 0 \%}$ & $\mathbf{3 0}$ & $\mathbf{1 0 0 \%}$ \\
\hline
\end{tabular}




\begin{tabular}{|c|c|c|c|c|c|}
\hline \multirow{5}{*}{ 2- Age (years) } & $18-27$ & 17 & 57 & 11 & 37 \\
\hline & $28-37$ & 10 & 33 & 16 & 53 \\
\hline & $38-47$ & 2 & 7 & 3 & 10 \\
\hline & $48-57$ & 1 & 3 & 0 & 0 \\
\hline & Total & 30 & $100 \%$ & 30 & $100 \%$ \\
\hline \multirow{4}{*}{$\begin{array}{l}\text { 3- } \\
\text { level }\end{array}$} & Secondary School of Nursing & 11 & 37 & 17 & 57 \\
\hline & Institution of Nursing & 9 & 30 & 7 & 23 \\
\hline & Bachelor of Science in Nursing & 10 & 33 & 6 & 20 \\
\hline & Total & 30 & $100 \%$ & 30 & $100 \%$ \\
\hline \multirow{6}{*}{$\begin{array}{l}\text { 4- Years } \\
\text { employment }\end{array}$} & Less than 5 years & 21 & 70 & 12 & 40 \\
\hline & $5-10$ & 5 & 17 & 8 & 27 \\
\hline & $11-15$ & 3 & 10 & 7 & 23 \\
\hline & $16-20$ & 0 & 0 & 1 & 3 \\
\hline & More than 20 & 1 & 3 & 2 & 7 \\
\hline & Total & 30 & $100 \%$ & 30 & $100 \%$ \\
\hline \multirow{10}{*}{$\begin{array}{l}\text { 5- Work site } \\
\text { (place of work / } \\
\text { ward) }\end{array}$} & General emergency & 4 & 13.3 & 0 & 0 \\
\hline & Paediatric emergency & 3 & 10 & 4 & 13 \\
\hline & Medical ward & 4 & 13.3 & 5 & 17 \\
\hline & Surgery ward & 3 & 10 & 0 & 0 \\
\hline & Paediatric ward & 3 & 10 & 4 & 13 \\
\hline & Haemodialysis unite & 4 & 13.3 & 4 & 13 \\
\hline & Operating Room & 3 & 10 & 4 & 13 \\
\hline & Obstetric and gynaecological & 4 & 13.3 & 0 & 0 \\
\hline & Other departments & 2 & 6.6 & 9 & 30 \\
\hline & Total & 30 & $100 \%$ & 30 & $100 \%$ \\
\hline
\end{tabular}

Table (2): Comparison between knowledge pre test scores for study and control groups regarding hepatitis B by using t-test at $P$-value $\leq 0.05$.

\begin{tabular}{|l|l|c|c|c|c|c|c|}
\hline \multirow{3}{*}{ Knowledge } & Group & No. & Mean & S.D & T cal. & T tab. & Sig. \\
\cline { 2 - 8 } & Study & 30 & 22.2667 & 6.64848 & \multirow{2}{*}{0.189} & 2.002 & \multirow{2}{*}{0.605} \\
\cline { 2 - 8 } & Control & 30 & 21.9667 & 5.57385 & & \\
\hline $\mathrm{DF}=58, \alpha=0.05$ &
\end{tabular}

Table (3): Comparison between knowledge post test scores for study and control groups regarding hepatitis B by using t-test at $P$-value $\leq 0.05$.

\begin{tabular}{||l|l|c|c|c|c|c|c|}
\hline \multirow{3}{*}{ Knowledge } & Group & No. & Mean & S.D & T cal. & T tab. & Sig. \\
\cline { 2 - 9 } & study & 30 & 42.1000 & 5.10139 & \multirow{2}{*}{14.921} & 2.002 & \multirow{2}{*}{0.000} \\
\cline { 2 - 8 } & control & 30 & 22.5333 & 5.05646 & & \\
\hline DF $=\mathbf{5 8 , \alpha}, \boldsymbol{\alpha}=\mathbf{0 . 0 5}$
\end{tabular}

Table (4): Association between knowledge post test knowledge scores in regard to hepatitis $B$ with (Gender) of the study group by using t-test at P-value $\leq 0.05$.

\begin{tabular}{|l|c|c|c|c|c|c|c|}
\hline \multirow{3}{*}{ knowledge } & Gender & No. & Mean & S.D & T cal. & T tab. & Sig. \\
\cline { 2 - 8 } & Male & 18 & 44.1667 & 4.81725 & 3.093 & 2.002 & \multirow{2}{*}{0.004} \\
\cline { 2 - 8 } & Female & 12 & 39.0000 & 3.90803 & & \\
\cline { 2 - 7 } & $\mathbf{D F}=\mathbf{2 8}, \boldsymbol{\alpha}=\mathbf{0 . 0 5}$ \\
\hline
\end{tabular}

Table (5): Analysis of variance of nurse's knowledge post test scores regarding (age ) of study group at at $P$-value $\leq 0.05$.

\begin{tabular}{|c|c|c|c|c|c|c|}
\hline \multirow{4}{*}{ Knowledge } & Source of variance & S. S & 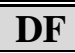 & Mean square & F. & Sig. \\
\hline & Between group & 110.365 & 3 & 36.788 & \multirow{3}{*}{1.484} & \multirow{3}{*}{0.242} \\
\hline & Within group & 644.335 & 26 & \multirow{2}{*}{24.782} & & \\
\hline & Total & 754.700 & 29 & & & \\
\hline \multicolumn{7}{|l|}{$P=\leq 0.05$} \\
\hline
\end{tabular}


Table (6): Analysis of variance of nurse's knowledge post test scores regarding ( Level of education) of study group at at $P$-value $\leq \mathbf{0 . 0 5}$.

\begin{tabular}{|l|c|c|c|c|c|c|}
\hline \multirow{3}{*}{ Knowledge } & Source of variance & S. S & DF & Mean square & F. & Sig. \\
\cline { 2 - 5 } & Between group & 142.073 & 2 & 71.0365 & & \multirow{2}{*}{3.131} \\
\cline { 2 - 5 } & Within group & 612.627 & 27 & 22.690 & \\
\cline { 2 - 5 } & Total & 754.700 & 29 & & \\
\hline $\mathbf{P}=\leq \mathbf{0 . 0 5}$ & & & & \\
\hline
\end{tabular}

Table (7): Analysis of variance of nurse's knowledge post test scores regarding (years of employment) of study group at at $P$-value $\leq 0.05$.

\begin{tabular}{||l|c|c|c|c|c|c|}
\hline \multirow{4}{*}{ Knowledge } & Source of variance & S. S & DF & Mean square & F. & Sig. \\
\cline { 2 - 5 } & Between group & 87.214 & 3 & 29.071 & \multirow{3}{*}{1.132} & \multirow{2}{*}{0.354} \\
\cline { 2 - 5 } & Within group & 667.486 & 26 & 25.673 & & \\
\cline { 2 - 5 } & Total & 754.700 & 29 & & \\
\hline $\mathbf{P}=\leq \mathbf{0 . 0 5}$ & \multicolumn{3}{|l}{} \\
\hline
\end{tabular}

Table (8): Analysis of variance of nurse's knowledge post test scores regarding (Place of work / unit) of study group at $P$-value $\leq \mathbf{0 . 0 5}$.

\begin{tabular}{|l|c|c|c|c|c|c|}
\hline \multirow{3}{*}{ Knowledge } & Source of variance & S. S & DF & Mean square & F. & Sig. \\
\cline { 2 - 5 } & Between group & 317.200 & 8 & 39.650 & \multirow{3}{*}{1.903} & \multirow{2}{*}{0.113} \\
\cline { 2 - 5 } & Within group & 437.500 & 21 & 20.833 & & \\
\cline { 2 - 5 } & Total & 754.700 & 29 & & \\
\hline
\end{tabular}

\section{DISCUSSION}

\section{Demographic Characteristics of the Sample:}

Throughout the course of data analysis, it depicted that more than two third of the study sample were males $(60 \%, 77 \%)$ in study and control groups respectively (table 1). This result is in agreement with study done by (Mohammed and Hassan, 2014), it is indicated that the majority of the study samples were males for study and control groups $(56.7 \%)(60 \%)$ respectively. The age group of (18-27) years old of the study group and for control group of ( 2837 ) years old accounted a highest proportion $(57 \%, 53 \%)$ respectively (table1). This age group is considered as an adult youth, which can provide and perform nursing intervention efficiently and correctly, since most of the nurses who have many years of service period move away to the primary health sector, the younger nurses could stay in the hospital care. These results are consistent with the study conducted by (Abdulla and Abdulla, 2014), who show that the largest proportion of the study samples were among age group (20-29). These results are consistent with other study that was conducted in Baghdad City by ( Badir and AlAni, 2012), who found that (53.3\%) of her study sample were age group (30-39) years. More than one third of nurses in study group and control group regarding their level of education had a secondary schools of nursing $(37 \%, 57 \%)$ respectively (table 1). These results are consistent with another study that was conducted in Kirkuk City by (Hassan and Hassan, 2012) who found that $(42.5 \%)$ of her study sample were graduated from secondary schools of nursing. Regarding the years of employment, the majority of them $(70 \%, 40 \%)$ has less than five years nursing service (table 1). These results are in agreement with the study conducted by (Abdulla and Abdulla, 2014), who found that the largest proportion of the study samples were between one to five years. (Hickam et al.,2003), claimed that Nurses' experience is more important than their educational levels. The Sample distributed almost evenly in all ward/ unit and emergency of the hospital (table 1) in study and control group. In the study group (13.3\%) for each of the General emergency, Medical ward, Hemodialysis unite, Obstetric and gynecological, and (10\%) for each of the Pediatric emergency, Surgery ward, Pediatric ward, Operating Room, (6.6\%) in other departments. And in the control group (13\%) were working in each of the Pediatric emergency, Pediatric ward, Hemodialysis unite, 
Operating Room, (17\%) in the Medical ward, (30\%) in other departments.

\section{Nurse's pre and post-test score}

Prior the implementation of the educational program, a pre-test was carried out on study and control groups. The study found that there is no significant difference between the two groups regarding HBV. It means that the nurses in both groups had the same knowledge about HBV (table 2). This result agrees with (Abdulla and Abdulla, 2014), this study showed that knowledge of nurses about HBV and uses of preventive measures was inadequate before the educational program, and improved after participation in the program.

After the implementation of the educational program on the study group, posttest was administered for both groups three weeks after the program. Results indicated that there is a highly significant difference in the post-test for study group (table 3). This indicates a positive effect and high compliance with the education program, and this means that the education program was effective on improving the nurses' knowledge. Similarly a quasi- experimental study conducted by (Abou Shady et al.,2001) in Mansoura , Egypt noticed a certain increase in staff's knowledge about viral hepatitis and their compliance with preventive precautions from pretest to post test. This study showed higher statistically significant differences between knowledge about universal precautions related blood and body fluids from pre and post education.

3.Study of variables of nurses and their effects an educational program in the posttest scores:

The difference between the several demographic characteristic of nurses and post test score were investigated and will be discussed here as follows:-

Table (4) show significant difference between mean and standard deviation of post test in male (44.1667) female (39.0000) regard to gender. These results indicated that the success rate of male nurses was higher than female nurses. It is known that most of female nursing staff in our country (Iraq) work in the gynecologic wards, in as much presence hepatitis B patients are mostly in the specializations departments (medical, surgical, pediatric, emergency) more than gyne department, therefore dealing of nurses who work in the specialization departments that deal with hepatitis B patients more than dealing the nurses in the gyne department with hepatitis B patients, and this was clear cause in regard to male nurses to acquiring knowledge more than female nurses because working mostly in the specialization departments leads to direct contact with hepatitis B patients that originate from experience, practice and daily skill that needed to theoretical knowledge. Table (5) show no significant difference between the posttest score of HBV knowledge with regard to age of nurses, most of nurses in the study group between (18-27) years old, this age considered young age that most of them had a few years of experience . which may be explained by the fact that younger nurses were comes with inexperience, inadequate knowledge and misconceptions regarding HBV. These results may also be explained by the fact that the information included in the program was clear, simple, and sufficient and it was appropriate for cognitive abilities of all age groups. This result disagrees with (Al-Augoidy, 2000), who stated that general and theoretical information increase as the age advance.Table (6) showed a significant difference in nurse's knowledge scores regarding the educational level in posttest of the study group at $\mathrm{P}$-value $\leq 0.05$. This means that educated nurses lead to high scores of knowledge. The level of education may affect the knowledge of nurses. This result agrees with (Mohamed and Wafa, 2011) who proved that there was significant correlation between posttest scores and the level of education of nurses.(Ghahramani et al., 2006) showed that there was a significant relationship between knowledge of hepatitis and educational level. Table (7) showed that there is no significant statistical difference in post - test scores between nurses knowledge with regard to their years of employment at $\mathrm{P}$-value $\leq 0.05$ in the study group. This result indicates that the effects of educational program make modification between nurse knowledge among different years of employment categories. This result agrees with (Al-Jubouri, 2014) who showed that concerning years of employment of nurse in the hospital, there is no relation at $\mathrm{P}>0.05$ between nurse's years of employment and their knowledge. This result also agrees with (ElDesouqi, 2004) who showed that the main causes of nurses poor performance were shortage of resources, nurses' level of knowledge and experience, high workload, lack of supervision or guidance and nurses' careless attitude. Table (8) showed that there was no significant statistical difference in nurse's knowledge scores regarding place of work /ward 
in post-test of the study group. The results indicated that the high proportion of the whole sample had less than 5 years of working in study and control groups (70\%- 40\%) respectively, this result may be due to the fact that there were many participants who did not spend enough time in clinical nursing to acquire better expertise of being executive Mentor. This result agrees with Ghahramani et. al. (2006) who showed who was no significant difference between knowledge of hepatitis and practices and position of nurses, place of work.

\section{CONCLUSION}

The study concluded the presence a deficiency of nurse's knowledge in general information regard to $\mathrm{HBV}$ before the implementation of the educational program in pre-test.The effect of the educational program was manifested throughout the acquisition of the nurse's knowledge after the implementation of the program. The study also concluded no Significant statistical differences have been found regarding HBV knowledge in post -test scores for nurse's demographic characteristics according to age, years of employment, place of work.

\section{RECOMMENDATIONS}

The study recommended to activating continuing nursing education unit or medical education as well as setting points and grades for these actions and calculating the promotion and annual increment as an equivalent point. Apply such educational health programs in all Iraqi governorate hospitals. It is recommended to have a booklet about the instructions and the rules to prevent the spread of $\mathrm{HBV}$ in all departments of the hospitals.

\section{REFERENCES}

Abdulla, S.; Abdulla, Z.(2014). Effect of an educational program on nurses' knowledge and practices toward Hepatitis B virus in emergency hospitals in Erbil. Zanco Journal Medical Science.18 (1). P.p.618-624.

Abou, Shady; Ibrahim, Y.; and Salem, Y. (2001). Implementation and evaluation of educational program for nurses regarding nosocomial infection control at Mansoura University Hospital. The New Egyptian Journal of Medicine. 24(5).P.p.226-233.

Abraham, J. (2012). Hepatitis B vaccine. Health Action. May. P.p.12-40.

AL-Augoidy, R.(2000).Quality Assurance of Nursing Care Thalassemia Children.
MSc Thesis University of Mosul. P.p.73-74.

Al-Jubouri, M. (2014). Assessment of Nurse's Knowledge about Nosocomial Infection at Hospitals in Baghdad City, Journal of Kufa for Nursing Science. 4 (1).

Askarian, M.; Yadollahi ,M.; Kuochak, F.; Danaei, M.; Vakili, V.; and Momeni, M. (2011). Precaution for health care workers to avoid hepatitis $\mathrm{B}$ and $\mathrm{C}$ virus infection. International Journal Occupational and Environmental Medicine. 2(4). P.p.191-198.

Aspinall, E.; Hawkins, G.; Fraser, A. Hutchinson, S.; and Goldberg, D. (2011) - Hepatitis B prevention, diagnosis, treatment and care. Journal of Occupational Medicine. P.p.531-540.

Badir , R.; Al- Ani, B. (2012). Impact of an Educational Program upon Nurses' Knowledge and Practices Concerning Neurogenic Bladder Rehabilitation for Spinal Cord Injured, Persons, University of Baghdad, College of Nursing, Iraqi National Journal of Nursing Specialties. 25 (2). P.p.74.

Beltrain, EM.; FCDC, and Alvardo-Rani. (2003). Public health service guideline for the management of occupational exposures to $\mathrm{HBV}, \mathrm{HCV}$, $\mathrm{HIV}$ and recommendation for post exposure prophylaxis. Morbidity and Mortality Weekly Report. P.p.1- 29.

Brown,R.; Gaglio, P. (2003). Scope of worldwide hepatitis C problem. Liver Transplntation 9 (11). P.p. 10-13.

Coffin,C.; Lee, S. (2006).Chronic Hepatitis B -Who Should Be Treated?. Med Gen Med. 8(1). P.p.75.

Dannetun, E., Tegnell, A. Torner, A., and Giesecke, J. (2006).Coverage of hepatitis B vaccination in Swedish healthcare workers, Journal of Hospital Infection. 63(2). P.p.201-204.

El-Desouqi, N. (2004).The Use of Continuous Quality Improvement Methodology to improve Nurses' Infection Control Practices at a General Hospital in Alexandria, published MSc Hospital Administration thesis of Alex. Univ. (EGY). High Inst. of Public Health. P.p.7

Ghahramani, F.; Mohammad, bergi, A.; and Mohammad Salehi , N. (2006). Survey of the Students' Knowledge about Hepatitis in Shiraz University of 
Medical Sciences. Hepatitis Monthly. 6(2). P.p.59-62.

Hassan, S.; Hassan, H. (2012). Effectiveness of nursing education program on nurses knowledge toward Arrhythmia in Kirkuk's teaching hospitals, College of Nursing, University of Kirkuk. kufa Journal for Nursing sciences. ISSN: 22234055. 2(3). P.p: 56-64.

Hickam, D.; Severance, S.; Feldstein, A.; Ray, L.; Gorman.P.; Schuldheis ,S.; and et. al. (2003).The Effect of Health Care Working Conditions on Patient Safety. Rockville, Md: Agency for Healthcare Research and Quality; Evidence Report/ Technology. Assessment 74. AHRQ publication 03-E031.

Mohamed, S.; Wafa, A. (2011).The Effects of an Educational Program on Nurses Knowledge and Practice Related to Hepatitis C Virus: A Pretest and Posttest Quasi-Experimental Design, Australian Journal of Basic and Applied Sciences. 5(11). P.p.564-570.

Mohammed, T.; Hassan,H. (2014) .Impact of Instructional Program on Nurses for Preventive Measures of Hepatitis (B and C) Infection Control in Medical City Hospitals. Kufa Journal for Nursing Science .4(2). P.p .75-85.

Nazzal, Z.; and Sobuh, I.(2014).Risk factors of hepatitis B transmission in northern Palestine: acase control study. Bio Med Central Research Notes. 7(1). P.p.190.
Perz, L.; Armstrong, G.; Farrington, L.; Hutin, Y.; and Bell, B. (2006).The contributions of hepatitis B virus and hepatitis $\mathrm{C}$ virus infections to cirrhosis and primary liver cancer worldwide. Journal of Hepatology. 45(4).P.p.529538.

SAVIC South African Vaccination and Immunization Centre (2008). disease hepatitis $B$.

Shepard, C.; Finelli, S.; Fiore, A.; and Bell, B. (2006). Hepatitis B Virus Infection: Epidemiology and Vaccination: Epidemiology Rev.2 8.P.p. 112-125.

Smith, D.; Ae- Choe, M.; Jeong, J.; Jeon, M.; Chae, Y.; and Ju An, G.( 2006). Epidemiology of Needle stick and Sharps Injuries Among Professional Korean Nurses. Journal of Professional Nursing. 22(6). P.p. 359-366.

Sreedharan, J.; Muttappallymyalil, J.; and Venkatramana, M. (2010). Knowledge and practice of standard measures in occupational exposure to blood and body fluids among nurses in a University Hospital in the United Arab Emirates. Italian Journal of Public Health.7 (1).P.p.90.

WHO. (2013). Hepatitis B , Factsheet $N^{\circ} 204$, Media center. Available:// www.who.int.

World Health Organization. (2012). Hepatitis B Fact sheet No 204. Revised. http://www.who.int/mediacentre/factshe ets/fs204/en/. 